\title{
Metal Artifact
}

National Cancer Institute

\section{Source}

National Cancer Institute. Metal Artifact. NCI Thesaurus. Code C87010.

An imaging artifact caused by a metal structure present in the scan field. 